Diánoia, vol. 6, no. 6, 1960

\title{
SAMUEL RAMOS Y EL HUMANISMO FILOSÓFICO DE MEXICO
}

Uno de los más notables recuerdos que tengo del XII Congreso Internacional de Filosofía, reunido en Venecia (septiembre de 1958), es, sin duda, la larga conversación privada que sostuve con Samuel Ramos, una tarde de sol, en la blanca sala de la Fundazione Cini (isla San Giorgio Maggiore). Gracias a mi apreciable amigo Eusebio Castro, que previno al maestro de mis deseos de conocerlo, pude solazarme con él. Desde hacía mucho tiempo conocía yo su fama y sus importantes obras. Quedé profundamente impresionado de la ardiente expresión de su fisonomía, que parecía invitar a la comunión de las conciencias, y de la insistencia con que me declaró que se consideraba, ante todo, como un esteta. Al día siguiente, en Padua, lo volví a ver con su hijo, momentos antes de la sesión solemne en la Sala dei Giganti al Liviano; ahí me hizo el presente de su tercera edición de El perfil del hombre y la cultura en México, amablemente dedicado... Quisiera aquí, en estos apresurados marginalia, no sólo rendir homenaje a su preclara memoria, sino también subrayar el alto sitio que ocupa su nombre en el seno de la filosofía actual.

Como bien lo observa el profesor René Lacroze, en su artículo sobre "La pensée mexicaine", "México se ha convertido en uno de los grandes centros de investigación filosófica, cuya influencia se proyecta por todo el continente iberoamericano". De hecho, la vasta República Mexicana; en el siglo xx, ha conocido una renovación del pensamiento filosófico. Después de la generación del Centenario y de (como dice Francisco Romero) sus "fundadores" José Vasconcelos y Antonio Caso, campeones del espiritualismo intuicionista del Ateneo de la Juventud y enemigos del viejo positivismo, siguió, en el tercer decenio del siglo, la generación de los Contemporáneos (nombre de una célebre revista), cuyos líderes eran Samuel Ramos y José Romano Muñoz, quienes dirigieron la reacción contra el antiintelectualismo y propusieron a los mexicanos el logro de una disciplina intelectual y el esfuerzo de una toma de conciencia nacional. Después de 1948, una tercera generación, la del grupo Hiperión, encabezado por Leopoldo Zea - de filiación orteguiana y hegeliana-, vino a tomar a su vez el relevo en la dirección de este poderoso movimiento de reflexión dialéctica.

Entre sus coetáneos, el llorado Samuel Ramos (1897-1959) pertenecía a una generación intermediaria del grupo de los mayores -influidos por el pensamiento francés (de Boutroux y de Bergson especialmente) - y el de

1 Publicado en Les Études Philosophiques (Paris, P.U.F., 1958, pág. 307), en el número especial dedicado a los "aspectos del pensamiento iberoamericano". 
los más jóvenes - vueltos más bien hacia el pensamiento alemán. "Una generación intelectual que comenzó a actuar públicamente entre 1925 y $193^{\circ}$ se sentía inconforme con el romanticismo filosófico de Caso y Vasconcelos. Después de una revisión crítica de sus doctrinas encontraba infundado el antiintelectualismo, pero tampoco quería volver al racionalismo clásico" - dice el maestro. ${ }^{2}$

Por otra parte, más o menos desde 1915, el nacionalismo mexicano recién fraguado se rehușó a admitir la posibilidad de filosofar a partir de lo intemporal y de lo universal, y reclamó por base de toda reflexión seria una atenta consideración del momento y de la tierra mexicanos. Como se ve, tales ideas guardan estrecho parentesco con las de Ortega y Gasset, cuyas Meditaciones del Quijote y El tema de nuestro tiempo hacian hincapié en la "situación" y en el hic et nunc, como indispensables para la comprensión adecuada del hombre individual o el colectivo ("yo soy yo y mi circunstancia"). Era la époça de la poesía de Ramón López Velarde, de la pintura de Diego Rivera, de la novela de Mariano Azuela, los tres enamorados del tema mexicano. Pero el abandono del pragmatismo afectivista de Caso - totalmente importado del extranjero- fue, para Ramos, una dolorosa ruptura con una filosofía que mucho habia amado (asi lo confiesa en su primera obra, Hipó. tesis, 1928). Pues, así como lo ha percibido atinadamente Patrick Romanell, se pueden distinguir, por lo menos, tres etapas en el itinerario espiritual de nuestro autor: el positivismo inicial (adoptado en Morelia, bajo el influjo de José Torres), abandonado desde 1916; el pragmatismo. (como que fue el más brillante discípulo de Caso) y el perspectivismo racio-vitalista e historicista, del que parece-que nunca renegó. ${ }^{3}$

Gon desprenderse de șus ideas de la juventud,' el profesor de la Univer: sidad Nacional Autónoma de México demostró ser un filósofo auténtico, sólo preocupado de la.verdad. Citemos a.Leopoldo Zea: "Ha sido un hombre de su tiempo, de ese tiempo que le tocó vivir, el del México de la Revolución mexicana en busca de su realidad y de su personalidad." 4 A la sazón había un material riquísimo, ya que el fascinante y gran país de los aztecas despertaba entonces al progreso y comenzaba a dirigirse por entero a alcanzar su plena promoción social e intelectual. A este respecto, es muy significativa una observación que hace el ex-rector de la Universidad de Madrid, José Gaos, porque muestra - bajo las aparentes analogias - la profunda diferencia que hay entre la España y el México modernos sobre el asunto tan ambiguo de la resurrección nacional: "El tema de Espạna es, para los pensadores españoles, el tema de una decadencia que hay que remediar, para muchos el tema de una grandeza que hay que restaurar, más que el de un nuevo progreso que

2 Historia de la filosofia en México, México, 1943, pág. 149.

3 La formación de la mentalidad mexicana, México, 1954, págs. 186-7.

4 La filosofía en México, México, 1955, t. I, pág. 73 . 
ir logrando. El tema de México es, para los pensadores mexicanos, el tema de independizarse de aquella decadencia no propia, para entrar sin obstáculos extraños por el camino de una grandeza que se promete, cuanto más nueva, tanto más segura." 5

La obra maestra de Samuel Ramos, El perfil del hombre y la cultura en México (1934), fue precisamente el eco inolvidable de esta doble preocupa. ción por la encarnación nacional de la filosofía y por la salud pública mediante la razón y la ética rigurosa. Con estilo apretado, bien dominado, este genial ensayo caracterológico, que dicta discretamente algunas lecciones de reforma psicológica y moral, en el que el humor no está ausente, recuerda un poco el método de Sieburg, en Dieu est-il français?, y también posee algo del severo diagnóstico de Taine, en sus Origines de la France contemporaine, aunque sin asomo de espíritu sectario o partidarista. Signo de controversia, esta obra notable, tan discutida pero tan sugestiva, ha abierto un campo nuevo a las investigaciones psicológicas y sociológicas, en una perspectiva que anuncia, en cierto sentido, la adoptada por Roger Bastide, quince años después, en su Sociologie et psychanalyse. Su mayor originalidad consiste en aplicar el método y las categorías de Alfred Adler al carácter del mexicanó, y en elaborar, por esto mismo, una filosofía de la cultura criolla. Según propias palabras de Samuel Ramos: "La idea del libro germinó en la mente del autor por un deseo vehemente de encontrar una teoría que explicara las modalidades originales del hombre mexicano y su cultura. Esta tarea implicaba una interpretación de nuestra historia, y conducía a descubrir ciertos vicios nacionales cuyo conocimiento me parece indispensable como punto de partida para emprender seriamente una reforma espiritual de México." * Ya se sabe cómo el maestro, haciendo oficio de psiquiatra ante una neurosis, descubrió en el mexicano un latente "sentimiento de inferioridad" y una continua "autodenigración", productos de la situación histórica de este joven pais, dividido entre dos filiaciones raciales del todo opuestas, mitad americana una, por lo indígena, mitad europea la otra, por la colonización española: al reaccionar contra esta fatal distorsión con un complejo de desaliento, resultado de sus repetidos esfuerzos por igualar a Europa o a los Estados Unidos de Norteamérica, el mexicano se engaña a sí mismo tomando la más. cara de una loca vanidad, mecanismo compensador de sus fracasos.

La desproporción entre el ideal que quiere alcanzar este audaz infortunado y el nivel demasiado humilde de sus posibilidades de realización provoca en este individualista introvertido una peligrosa tensión que lo lleva insensiblemente al pesimismo endémico y a la falsa jactancia patriotera que es su correlato. Derivada de la península ibérica, por el camino de la imitación

5 En torno a la filosofia mexicana, México, 1953, t. II, pág. $6_{5}$.

6 El perfil del hombre..., prólogo a la tercera edición, pág. 10. 
y de la asimilación, la cultura mexicana es heterogénea e inestable, un producto desconcertante de la mezcla íntima de la herencia indígena y de la aportación de los conquistadores hispanos; por eso se ve vinculada muy a menudo a comportamientos anormales, como el "machismo", por ejemplo. A este respecto, los capítulos sobre el psicoanálisis del mexicano, en sus tres tipos: el "pelado", la clase media y el burgués (págs. 50-65), y también el capítulo sobre la cultura criolla (págs. 66-82) constituyen un modelo de disección psicológica. El maestro expone, por otra parte y con mucha fuerza, cómo esta funesta "desconfianza" es injustificada, y muestra hasta qué punto los dones intelectuales de los mexicanos les permitirian tener con honor su rango en el concurso internacional, por poco que supieran ver claro en sí mismos y midieran racionalmente sus ambiciones. "Creo — dice Ramos- en la salvación de México, porque nuestra raza no carece ni de inteligencia ni de vitalidad; lo único que le falta es aprender. Pero la sabiduría que le es necesaria no es la que se aprende en las escuelas, sino una cierta sabiduría que sólo la experiencia puede dar." 7

Pero el despiadado cuadro de semejante situación patológica se completa con una terapéutica, cuyos grandes rasgos están magistralmente delineados en la segunda parte del libro. Si bien admite Ramos un determinismo tan estricto del medio y de las condiciones biológicas, económicas y sociales, no llega, sin embargo, hasta el necesitarismo' integral: "Dentro de los marcos inflexibles que la vida impone a cada individuo, existe un pequeño margen para que disponga libremente de sus actos." \& De aquí el enunciado de algunos principios de regeneración nacional, por medio de la cura de almas y la reeducación a radice. "Sólo podremos conocernos a nosotros mismos como individuos o como pueblo, cuando a nuestras pequeñas pasiones podamos oponer la gran pasión de la verdad, que es una de las formas del amor desinteresado hacia las personas y las cosas, reales o aun ideales; amor por el conocimiento cuyo símbolo mejor es el eros platónico." 9

De este modo el mexicano queda invitado al examen de conciencia y, además, a luchar contra su desesperación, su miseria, su pereza, su oscurantismo, y a ir decididamente de abajo hacia arriba, en vez de esperar de fuera su liberación. En esta perspectiva, sería necesario releer las nobles páginas dedicadas al deber de sinceridad (págs. 99-102). Samuel Ramos propone a las almas que están en vías de liberarse, un "nuevo humanismo", forjado a base de una elevada cultura espiritual, y las pone en guardia contra la ilusoria tentación del tecnicismo integral, inspirado en el fáustico Wille zur Macht y por un grosero naturalismo. ¿Cómo no pensar aqui, más todavía que en

7 Ibid., pág. 16.

8 Ibid., pág. 11.

9 Ibid., pág. 92. 
G. Duhamel, H. Dubreuil, A. Huxley o A. Maurois, en las justas advertencias de Emmanuel Mounier, en su Revolution personnaliste et communautaire y en su revista Esprit?

Efectivamente, la mayéutica del profesor de la Universidad Nacional Autónoma de México no sólo es valiosa para su patria, sino para toda la humanidad. Ramos confiesa: "Tendremos que buscar el conocimiento del mundo en general, a través del caso particular que es nuestro pequeño mundo mexicano. Se equivocaría el que interpretara estas ideas como mera expresión de un nacionalismo estrecho." to Por lo demás, en Hacia un nuevo hu. manismo (1940), se ha explicado suficientemente el contenido y los principios de este humanismo renovado, cuya defensa representa, a los ojos de Ramos, el tema central de toda filosofía fiel a su vocación. Se trata, en resumen, de la esencia del hombre $y$ de las opciones que se nos proponen al respecto. Samuel Ramos establece aquí, desde el principio, que la crisis de nuestro tiempo es la del humanismo: la idea misma del hombre ha sido modificada de parte a parte, en nuestros días. La tradición filosófica, tres veces milenaria, enseñaba la primacia del espíritu sobre la materia en esa mezcla extraña que es el hombre; pero en nuestra época se manifiesta un retroceso, porque vemos a los valores sensibles y pragmáticos tomar bárbaramente esa primacía. La solución es buscar "el restablecimiento de la armonía, desde luego en el ser individual del hombre y en seguida en su existencia histórica". Como Fray Luis de León, deseoso de que se opere por fin la concordia interior y exterior de los seres, Samuel Ramos preconiza la sintesis de las tendencias contrarias en el seno del hombre, bajo el magisterio de la razón, cuyo poder deberá ser por fin totalmente restituido. Intérprete convencidísimo de una filosofía de la persona, que se vincula muy estrechamente con Max Scheler y con Nicolai Hartmann, el maestro integra en su visión del mundo la analítica heidegge. riana del Dasein y reduce a un orden discursivo los más importantes sistemas doctrinales de la actualidad, de Boutroux y Bergson al existencialismo, pasando por el neokantismo de las escuelas de Marburgo y de Baden, por la fenomenología de Husserl y la filosofía axiológica.

Permitaseme en este punto, porque soy francés, asociarme con todo el corazón a la alabanza dirigida a Samuel Ramos por José Gaos, quien escribe a este respecto: "En este punto, reivindicación de Boutroux y Bergson como antecesores de la filosofía existencial. Justo tributo de gratitud a la filosofía francesa a que Samuel Ramos debe tan buena —en todos sentidosparte de su formación, y reivindicación justa en sí, que la filosofía más reciente no ha dejado de hacer enteramente." 11 Esta es, por otra parte, la misma simpatía con que gocé páginas tan finas como las consagradas por Ramos, en El perfil del hombre... (págs. 41-9), a las profundas afinidades

10 Ibid., págs. 134-5.

11 Pensamiento de lengua española, México, 1945, págs. 176-7. 
del espíritu mexicano y el francés, debidas a la mediación del espíritu latino y clásico, al que yo me siento indefectiblemente ligado.

La misma fuente de un humanismo auténtico, que comprende todas las dimensiones de la condición humana y está ordenado a los valores espirituales, se encuentra subyacente en la bella Historia de la filosofia en México (1943), donde se rinde tanta justicia a Gamarra, y cuyo prólogo constituye un documento singularmente interesante para conocer las posiciones de Ramos mismo. Se podría encontrar también tal constante preocupación en Más allá de la moral de Kant (1998), en Veinte años de educación en México (1941), en Filosofía de la vida artistica (1950), en El problema del "a priori" y la experiencia (1955) y hasta en uno de los últimos artículos que escribió el maestro, Concepto y método de la metafisica de Heidegger, en donde trata con toda claridad el inevitable problema del ser: "Bien que nuestro tiempo se jacte de haber restaurado la metafísica, ha omitido plantearse con todo rigor la pregunta que interroga sobre lo que es el ser. A primera vista parece extraño este proceder, ya que aquella cuestión constituye el problema central de toda metafisica." 12 Así, pues, lejos de ser un análisis negativo de la psique mexicana, El perfil del hombre... se entrega por entero a una empresa de renovación filosófica, llena de luz y de esperanza y deliberadamente orientada hacia el espiritualismo de los valores, cuyo mensaje austero, pero seguro, aparece como susceptible, en México como en otras partes, de aportar, sin ningún exclusivismo, la salvación a los hombres de buena vo. luntad.

Apóstol de la regeneración intelectual y moral de su país, Samuel Ramos ha ejercido y ejercerá, durante muchísimo tiempo todavía, una profunda influencia en toda la hispanidad. Por ejemplo, su libro clave ha incitado pro. bablemente al renombrado psiquiatra madrileño Juan José López Ibor a redactar su curiosa obra sobre El español y su complejo de inferioridad (1951). Nadie ignora cuán brillantemente ha prolongado y elaborado Leopoldo Zea la dirección iniciada por Ramos. Zea en sus grandes tratados, El positivismo en México (1943), En torno a una filosofía americana (1946), Dos etapas del pensamiento en Hispanoamérica (1949), Conciencia y posibilidad del mexi. cano (1952), América como conciencia (1953), etc..., ha abarcado enteramente al homo mexicanus y aun al homo americanus, valido de los métodos crí. ticos más precisos de la antropología filosófica contemporánea. Maestros tan eminentes como son Eduardo Garcia Máynez (director del Centro de Es. tudios Filosóficos de la Universidad Ncional Autónoma de México y gran filósofo del derecho), Edmundo O'Gorman (el filósofo historiador de la América Hispánica) o Emilio Uranga (el autor del Análisis del ser del me. xicano) parecen igualmente haber escuchado el llamado de Samuel Ramos. Espíritu de vanguardia y pensador exigente, el gran universitario mexicano,

12 Revista Mexicana de Sociología, Núm. 1, 1958, pág. 51. 
prematuramente desaparecido, ha sabido dar raro ejemplo de sabiduría sin demagogia ni compromisos; su divisa habría podido ser la misma de Unamuno: "Verdad más que paz"; su obra y su influencia testimonian ampliamente el alto nivel alcanzado, desde hace un cuarto de siglo, por la filosofía mexicana.

Alain GuY (trad. Huberto Batis) 